\title{
XXV. Further illustrations of a method for computing magnetic declination, on the principle proposed by Professor Gauss
}

\section{Samuel Beswick}

To cite this article: Samuel Beswick (1850) XXV. Further illustrations of a method for computing magnetic declination, on the principle proposed by Professor Gauss, Philosophical Magazine Series 3, 36:242, 183-190, DOI: 10.1080/14786445008646458

To link to this article: http://dx.doi.org/10.1080/14786445008646458

曲 Published online: 30 Apr 2009.

Submit your article to this journal $\pi$

Џ Article views: 1

Q View related articles $\sqsubset$ 
in attempting to refer the facts observed by Mr. Faraday* to the optical axis, inverts the right course of proceeding; the attraction or repulsion of this axis being a secondary result, depending first of all upon the magnetism or diamagnetism of the substance, and secondly upon the manner in which either force is modified by the peculiar structure of the crystal.

The conducting power, so to speak, of Iceland spar for both magnetism and diamagnetism appears to be in directions perpendicular to the lines of cleavage. If these views be correct, the optical axis can no longer be regarded as the prime agent in the production of the phænomena which we bave been considering; we shall no longer seek the explanation of new facts in the hypotheses of new forces, but rather in modifications of the old.

Marburg, January 1850.

XXV. Further Illustrations of a Method for computing Magnetic Declination, on the principle proposed by Professor Gauss. By Samuel Beswuck $\nmid$.

TN my former communication I gave two illustrations of a 1 new method whereby the mean declinations at Greenwich and St. Helena, for the past year 1849, were computed with the utmost exactitude. But the utility of this new method consists, not only in its simplicity and precision, but also in its applicability to all places in the two hemispheres, and to all epochs, past, present, and to come. To obtain the declination all over the world, at an epoch so distant as the time of Columbus (see the first illustration), or of one hundred, or even one thousand years in the future, there needs no additional data, nor any alteration in the method: there are only the same number of items : and the result is obtained equally easy, and in the same time, as if the declination was being obtained for the present year. Time and place make no difference in the length or nature of the computation.

If, therefore, this paper be favoured with the attention of the Committee appointed to conduct the co-operation of the British Association in the system of Simultaneous Magnetical and Meteorological Observations, I trust they will kindlynotice, not only the above observations, but also the following advantageous characteristic of this new method over all others, viz. to compute the declination all over the world, for any epoch, however remote the time may be, not a single observa-

- Phil. Mag., Jan. 1849, p. 75.

+ Communicated by the Author. 


\section{Mr. S. Beswick's further Illustrations of a Method}

tion of any kind is required. The two accompanying illustrations are intended as proof of its advantageous superiority in this particular. Colonel Sabine has kindly reminded me of the grand desideratum in this department of science, for the accomplishment of which enormous labours have been undertaken, and considerable sums of money annually expended,that "the chief difficulty in any empirical formula would be to adapt it to different epochs." I have thought it necessary, in consequence of this remindal, - and with a view to the complete exposition of the method I propose, and to the clear understanding of the important practical advantages it offers over all others, - to present a few general explanatory remarks, accompanied with two distinct proofs of its application to different epochs. Which proofs are intended to show, that this ' chief difficulty' is completely removed; indeed so completely, that not a single item would be added to the process, nor even altered in its form, whether the epoch was three years in the past, or three hundred years in the future.

I am desirous of recording a matter of considerable importance in this paper, to which I solicit the kind attention of the gentlemen forming the Committee for Simultaneous Magnetical and Meteorological Observations referred to above. The obvious failure of all previous methods, after the interval of a few years, mainly results from a quarter which, up to the present time, is not even suspected. It is this-the southern magnetic point of convergence of the horizontal force, or pole, does not revolve from east to rest, as hitherto supposed; on the contrary, both poles move in the same direction from west to east. Hence, if the numerical coefficients of Prof. Gauss's general theory be reconstructed-the necessity of which is suggested by Colonel Sabine*,-it can never become available for practical purposes, except for the time being, in consequence of this fundamental error. Every formula should be required to prove its utility by its application to successive epochs of 50 or 100 years interval for 300 years past, before it be relied on in its applications to the future. Should this test be admitted, then my investigations into this matter enable me to state, that the general formula of Gauss, and of all others which suppose a revolution of the southern magnetic pole from $E$. to $W$., will prove, during the test, an entire failure. I would respectfully suggest to the Committee of Observation, that every method be required to fulfill the demands of this test.

We will now try the merits of our own method by this rule; and, in so doing, we wish to be followed by all others pro-

- Phil. Trans., part 2, 1849. 
posing to compute magnetic declination. The epochs selected are the years 1492 and 1722 : the first is 357 years in the past, and the latter 127 years. The epoch of 1492 refers to the celebrated discovery of the magnetic line of no declination, during the first yoyage of Columbus; and the epoch of 1722 refers to Graham's excellent observations on the declination of the needle at London. The epochs are as memorable as any in the history of terrestrial magnetism, and are as widely distant from each other, and from the present, as any which can be selected for the trial we propose.

In the first place, we will state the data on which we ground the adaptation of our method to different epochs. The data simply consist in discovering the annual velocity of the north and south magnetic poles; for when this is obtained, their situation at any given epoch is easily found, by multiplying the annual velocity of each by the number of years intervening between the epoch and a given year (1849), when their relative situation is known. After a long and almost hopeless investigation, I have ascertained the velocity in longitude of the north magnetic pole to be double that of the magnetic pole in the southern hemisphere, and that both have had a diminishing velocity, with occasional exceptions*, since the epoch of 1492. The rule for computing the velocity and situation of the two poles is as follows:-Commencing with the year 1460, multiply the whole interval between that year and 1849 (389 years) by seventeen minutes; and for every successive diminution of 60 years in that interval, lessen the multiplying number one minute, as in the following table. The fixed epoch by which the interval is determined is the past year 1849.

Forall epochs between 1460 and 1520 multiply the interval by $17^{\prime}$.

$\begin{array}{ccccccc}\ldots & \ldots & 1520 \ldots 1580 & \ldots & \ldots & 16^{\prime} . \\ \ldots & \ldots & 1580 \ldots 1640 & \ldots & \ldots & 15^{\prime} . \\ \ldots & \ldots & 1640 \ldots 1700 & \ldots & \ldots & 14^{\prime} . \\ \ldots & \ldots & 1700 \ldots 1760 & \ldots & \ldots & 13^{\prime} . \\ \ldots & \ldots & 1760 \ldots 1820 & \ldots & \ldots & 12^{\prime} . \\ \ldots & \ldots & 1820 \ldots 1880 & \ldots & \ldots & 11^{\prime} .\end{array}$

This table is only for the north magnetic pole; in all cases the multiplying number for the south magnetic pole must be one-half the multiplying number for the opposite pole. The mean positions of the two magnetic poles for the fixed epoch 1849 , are as follows :-

* Grover's memoir, Orbital Motion of the Magnetic Pole round the North Pole of the Earth, read at the Nineteenth Annual Meeting of the British Association held at Birmingham, 1849. 
North magnetic pole, lat. $70^{\circ} 0^{\prime}$ : west long. $91^{\circ} 0^{\prime}$. South magnetic pole, lat. $75^{\circ} 5^{\prime}$ : east long. $155^{\circ} 0^{\prime}$.

In taking the epoch of 1492 , we shall have an interval of 357 years, which, multiplied by the rate of revolution in lon-

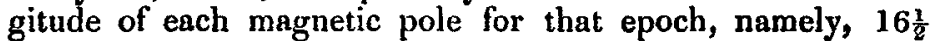
minutes annually for the northern, and $8 \frac{1}{4}$ minutes annually for the southern, will give $98^{\circ} 10^{\prime}$ for the former, and $49^{\circ} 5^{\prime}$ for the latter: hence, if the magnetic poles be removed backwards in west longitude by so much as the amounts stated above, we shall then have their relative positions for the year 1492 as follows :-

1849, N. M. pole, W. long. $91^{\circ} 0^{\prime}$ : S. M. pole, E.long. $155^{\circ} 0^{\prime}$ 1492, N.M.pole, W. long. $189^{\circ} 10^{\prime}$ : S.M.pole, E.long. $\frac{49^{\circ} \quad 5^{\prime}}{105}$

This preliminary is all which is necessary for the adaptation of our method to any given epoch, past or to come. In the present case it is applied to one of the most memorable in nautical astronomy - the discovery of the line without magnetic variation. The merit of this discovery belongs to Christopher Columbus, who crossed it whilst on his celebrated first voyage for the discovery of a western route to the Indies. We think it would be advisable for the Committee of Magnetical Observation to make this epoch the test of all methods proposing to compute magnetic declination; for the question naturally presents itself-how shall we best prove a method but by its application to the recorded observations of the past; and what observation is more memorable than the one here proposed? This eminent navigator has recorded the position of this line in the year of his first voyage, September 25, 1492, in the following words:-

" $2 \frac{1}{2}^{\circ}$ west of the island of Corvo, the magnetic variation changed and passed from N.E. to N.W."

We propose to test our method by trying whether it will find this line in the same spot at the time stated. An explanation of the process having been fully stated in the former article, it is useless to give a repetition in the present instance. It will be observed, however, that corresponding items with those previously given are here arranged under corresponding numbers.

Mean Declination of the Compass Needle on the Atlantic during the voyage of Christopher Columbus for the epoch of Sept. 25, 1492 .

(1.) Lat. and long. of position.

$$
\begin{aligned}
& \text { N. lat. } 27^{\circ} 0^{\prime} \text { : comp. } 63^{\circ} \text {. } \\
& \text { W. long. } 31^{\circ} 30^{\prime} \text {. }
\end{aligned}
$$


(2.) Lat. and long. of N. magnetic pole.

N. lat. $70^{\circ}$ : comp. $20^{\circ}$.

W. long. $91^{\circ}+98^{\circ} 10^{\prime}-31^{\circ} 30^{\prime}=157^{\circ} 40^{\prime}$.

$$
157^{\circ} 40^{\prime}-90^{\circ}=67^{\circ} 40^{\prime} \text {. }
$$

sine $20^{\circ} 0^{\prime}$. . . . . 953405 sine $67^{\circ} 40^{\prime}$. . . . 996614

sine $18^{\circ} 27^{\prime}$. . . . $\overline{950019}$

(4.) Lat. and long. of S. magnetic pole.

S. lat. $75^{\circ} 5^{\prime}$ : comp. $14^{\circ} 55^{\prime}$.

E. long. $155^{\circ}-49^{\circ} 5^{\prime}+31^{\circ} 30^{\prime}=137^{\circ} 25^{\prime}$.

$$
\begin{aligned}
& 137^{\circ} 25^{\prime}-90^{\circ}=47^{\circ} 25^{\prime} \text {. } \\
& \text { sine } 14^{\circ} 55^{\prime} \text {. . . . 941063 } \\
& \text { sine } 47^{\circ} 25^{\prime} \text {. . . . } 986705 \\
& \text { sine } 10^{\circ} 56^{\prime} \text {. . . . } \overline{927768}
\end{aligned}
$$

$$
63^{\circ}+18^{\circ} 27^{\prime}=81^{\circ} 27^{\prime} \text {. }
$$$$
81^{\circ} 27^{\prime} \times 20^{\prime \prime}=27^{\prime} 9^{\prime \prime}
$$

$$
20^{\circ} 0^{\prime} \times 1^{\prime}=\frac{20^{\prime} 0^{\prime \prime}}{47^{\prime} 9^{\prime \prime}}
$$

$$
\begin{aligned}
& 180^{\circ}+16^{\circ} 27^{\prime}+10^{\circ} 56^{\prime}=209^{\circ} 23^{\prime} . \\
& 32400: 43841:: 47^{\prime} 9^{\prime \prime}: 63^{\prime} 47^{\prime \prime} . \\
& 63^{\prime} 47^{\prime \prime} \times 81^{\circ} 27^{\prime} \div 10^{\circ}=8^{\circ} 51^{\prime} . \\
& 20^{\circ}+8^{\circ} 51^{\prime}=28^{\circ} 51^{\prime} . \\
& 4900^{\circ}: 110^{\circ}:: 729^{\circ}: 16^{\circ} 21^{\prime} . \\
& 90^{\circ}: 16^{\circ} 21^{\prime}:: 8^{\circ} 51^{\prime}: 1^{\circ} 36^{\prime} . \\
& 157^{\circ} 40^{\prime}-1^{\circ} 36^{\prime}=156^{\circ} 4^{\prime}: \text { comp. } 23^{\circ} 56^{\prime} .
\end{aligned}
$$

sine $63^{\circ} \mathrm{O}^{\prime} \quad$ • . . . 994988 sine $23^{\circ} 56^{\prime}$. . . . . 960818 sine $21^{\circ} 12^{\prime}$. . . . $\overline{955806}$

sine of comp. and rad. $23^{\circ} 56^{\prime}$. . 1996095 tang. to comp . . . $63^{\circ} 0^{\prime}$. . 970717 tang. . . . . . $60^{\circ} 52^{\prime}$. . $\overline{1025378}$

$$
60^{\circ} 52^{\prime}+28^{\circ} 51^{\prime}=89^{\circ} 43^{\prime} \text {. }
$$

sine to comp. $21^{\circ} 12^{\prime}$. . . . 996957

sine to comp. $89^{\circ} 43^{\prime}$. . . . 769417

sine to comp. $89^{\circ} 44^{\prime}$. . . . . $\overline{766374}$ 
188 Mr. S. Beswick's further Illustrations of a Method

(12.)

$$
\begin{aligned}
& \text { sine } 28^{\circ} 51^{\prime} \text {. . . . } 968351 \\
& \text { sine } 23^{\circ} 56^{\prime} \text {. . . . } 960818 \\
& 1929169 \\
& \text { sine } 89^{\circ} 44^{\prime} \text {. . . } 1000000 \\
& \text { sine } 11^{\circ} 17^{\prime} \text {. . . . } \overline{929169}
\end{aligned}
$$

We must now find the sides and angles for the southern hemisphere.

$$
\begin{aligned}
& 63^{\circ}-10^{\circ} 56^{\prime}=52^{\circ} 4^{\prime} . \\
& 52^{\circ} \quad 4^{\prime} \times 20^{\prime \prime}=17^{\prime} 21^{\prime \prime} \\
& 14^{\circ} 55^{\prime} \times 1^{\prime}=\frac{14^{\prime} 55^{\prime \prime}}{32^{\prime} 16^{\prime \prime}}
\end{aligned}
$$

$$
\begin{aligned}
& 180^{\circ}+18^{\circ} 27^{\prime}+10^{\circ} 56^{\prime}=209^{\circ} 23^{\prime} \text {. } \\
& 32400 \text { : } 43841 \text { : : } 32^{\prime} 16^{\prime \prime}: 43^{\prime} 39^{\prime \prime} \text {. } \\
& 43^{\prime} 39^{\prime \prime} \times 52^{\circ} 4^{\prime} \div 10^{\circ}=3^{\circ} 47^{\prime} \text {. } \\
& 14^{\circ} 55^{\prime}+3^{\circ} 47^{\prime}=18^{\circ} 4,2^{\prime} \text {. } \\
& 5637^{\circ}: 104^{\circ} 55^{\prime}:: 727^{\circ}: 13^{\circ} 31^{\prime} \text {. } \\
& 90^{\circ}: 13^{\circ} 31^{\prime}:: 3^{\circ} 47^{\prime}: 34^{\prime} \text {. } \\
& 137^{\circ} 25^{\prime}+34^{\prime}=137^{\circ} 59^{\prime} \text { : comp. } 42^{\circ} 1^{\prime} \text {. } \\
& \text { sine } 63^{\circ} 0^{\prime} \quad \text { • . . . } 994998 \\
& \text { sine } 42^{\circ} 1^{\prime} \quad . \quad . \quad . \quad .982565 \\
& \text { sine } 36^{\circ} 37^{\prime} \text {. . . . } \overline{\mathbf{9 7 7 5 6 3}}
\end{aligned}
$$

sine to comp. and rad. $42^{\circ} 1^{\prime}$. . 1987096

tang. to comp. . . . $63^{\circ} 0^{\prime}$. . 970717

tang. . . . . . 55 $33^{\prime}$. . $\overline{1016379}$

$$
55^{\circ} 33^{\prime}-18^{\circ} 42^{\prime}=36^{\circ} 51^{\prime} \text {. }
$$

sine to comp. $36^{\circ} 37^{\prime}$. . . . 990452

sine to comp. $36^{\circ} 51^{\prime}$. . . . 990320

sine to comp. $50^{\circ} 2^{\prime}$. . . . $\overline{980772}$

The comp. of $180^{\circ}$ is $129^{\circ} 58^{\prime}$.

$$
\begin{aligned}
& \text { sine } 18^{\circ} 42^{\prime} \text {. . . . } 950598 \\
& \text { sine } 42^{\circ} 1^{\prime} \text {. . . . } 982565 \\
& \overline{1933163} \\
& \text { sine } 50^{\circ} 2^{\prime} \text { - . . . } 988447 \\
& \text { sine } 16^{\circ} 15^{\prime} \text {. . . . } \overline{944716}
\end{aligned}
$$




$$
\begin{aligned}
& \text { Sides. Angles. } \\
& 89^{\circ} 44^{\prime} \quad 11^{\circ} 17^{\prime} \\
& 129^{\circ} 58^{\prime} \quad 16^{\circ} 15^{\prime} \\
& \overline{219^{\circ} 42^{\prime}}: \overline{27^{\circ} 32^{\prime}} \text { : : } 89^{\circ} 44^{\prime}: 11^{\circ} 14^{\prime} \text {. } \\
& 11^{\circ} 17^{\prime} \\
& 11^{\circ} 14^{\prime} \\
& 3^{\prime} \text { W. D., }
\end{aligned}
$$

which is the mean west declination on the Atlantic for the year 1492. It may be objected-Columbus affirms there was no declination, whilst your method gives 3 minutes. Suppose we grant this, it is only an error of 3 minutes in 357 years, or $\frac{1}{2}$ a second annually; an amount so small, that in ordinary practice even the whole would be scarcely noticed. But, reader, this error does not exist. These three minutes show the mean declination for the whole year; in other words, it is the declination for about the middle of the year-say June: and as the diminution was then going on at the rate of sixteen and a half minutes per year, the three minutes rould just have vanished at the close of the month of September. Accordingly Columbus discovered the line when passing this spot on the 25th of September. Hence there is not even a second of difference between the observation and our calculation, though it involves so great an interval as 357 years. The next illustration is for the epoch of 1722 , involving an interval of 127 years. In this instance we shall not go through the whole computation, but merely state the result as given in item 13 . It is as follows :-

$$
\begin{aligned}
& \text { Sides. Angles. } \\
& 52^{\circ} 30^{\prime} \quad 26^{\circ} 51^{\prime} \\
& \begin{array}{llll}
152^{\circ} 4 !^{\prime} & 22^{\circ} \quad 7^{\prime}
\end{array} \\
& \overline{205^{\circ} 11^{\prime}}: \overline{48^{\circ} 58^{\prime}}: \text { : } 52^{\circ} 30^{\prime}: 12^{\circ} 31^{\prime} \text {. } \\
& 26^{\circ} 51^{\prime} \\
& 12^{\circ} 31^{\prime} \\
& \overline{14^{\circ} 20^{\prime}} \text { W. declination, }
\end{aligned}
$$

which is the mean declination for London, 1722 .

In the observations of Graham, inserted in the Philosophical Transactions, No. 383, p. 96, for 1724, the mean declination is the same as given in our computation, namely $14^{\circ} 20^{\prime}$ west.

As before observed, the epochs we have taken are as memorable as any in the history of terrestrial magnetism, and are as widely distant from each other, and from the present, 
190 The Rev. Brice Bronwin on the Theory of the Tides.

as any which can be selected for the trial we propose for all methods computing magnetic declination. I would therefore respectfully suggest to the Magnetical Committee of Observation, that every method be required to fulfill the demands of this test.

Manchester, Feb. 15, 1850.

XXVI. On the Theory of the Tides. By the Rev. Brice Bronwin.

[Continued from vol. xxxv. p. 345.]

A $T$ the close of my last paper on the 'Theory of the Tides, A I expressed an intention of examining the terms of the second order, considering that there might be some among them which might produce a sensible effect. This I have now done, but do not find any so large as I had anticipated; still they may be sufficiently large to have a sensible effect on the largest of the variable terms in the coefficients, and ought therefore to be noticed.

Neglecting quantities of the third order, and those of the second where $s$ enters, and also putting $\alpha=1, p=1$, we have Méc. Cél., book 1. chap. 8, No. 35,

Also

$$
\sigma^{\prime}=1+\frac{d s}{d r}+\frac{d u}{d \theta}+\frac{d v}{d \sigma}+\frac{d u}{d \theta} \frac{d v}{d \sigma}-\frac{d u}{d \omega} \frac{d v}{d \theta} .
$$

$$
\sin \theta^{\prime}=\sin (\theta+u)=\sin \theta+u \cos \theta-\frac{1}{2} u^{2} \sin \theta, \quad r^{\prime}=r+s .
$$

These values being substituted in

$$
6^{\prime} r^{\prime 2} \sin \theta^{\prime}=r^{2} \sin \theta
$$

neglecting the same quantities as before, and leaving out the term $\frac{d\left(r^{2} s\right)}{d r}$, we find

$$
\begin{gathered}
\frac{d u}{d \theta}+\frac{d v}{d \sigma}+\frac{u \cos \theta}{\sin \theta}+\frac{d u}{d \theta} \frac{d v}{d \sigma}-\frac{d u}{d \sigma} \frac{d v}{d \theta}+u \frac{u u \cos \theta}{d \theta} \frac{\cos }{\sin } \\
+u \frac{d v}{d \sigma} \frac{\cos \theta}{\sin \theta}-\frac{1}{2} u^{2}=0 .
\end{gathered}
$$

Such is now the equation of continuity; in the terms of the first order change $u$ and $v$ into $u+\Delta u$ and $v+\Delta v$. With these values, leaving out the resulting terms of the first order, the last equation gives

$$
\left.\begin{array}{c}
\frac{d \Delta u}{d \theta}+\frac{d \Delta v}{d \sigma}+\frac{\Delta u \cos \theta}{\sin \theta}+\frac{d u}{d \theta} \frac{d v}{d \sigma}-\frac{d u}{d \sigma} \frac{d v}{d \theta}+\frac{u \cos \theta}{\sin \theta} \\
\left(\frac{d u}{d \theta}+\frac{d v}{d \sigma}\right)-\frac{1}{2} u^{2}=0 .
\end{array}\right\}
$$

